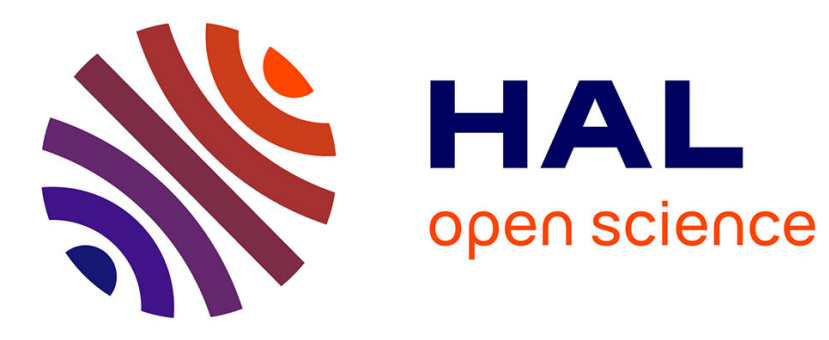

\title{
Optimal power dispatching strategies in smart-microgrids with storage
}

Rémy Rigo-Mariani, Bruno Sareni, Xavier Roboam, Christophe Turpin

\section{To cite this version:}

Rémy Rigo-Mariani, Bruno Sareni, Xavier Roboam, Christophe Turpin. Optimal power dispatching strategies in smart-microgrids with storage. Renewable and Sustainable Energy Reviews, 2014, vol. 40, pp. 649-658. 10.1016/j.rser.2014.07.138 . hal-01064368

\section{HAL Id: hal-01064368 https://hal.science/hal-01064368}

Submitted on 16 Sep 2014

HAL is a multi-disciplinary open access archive for the deposit and dissemination of scientific research documents, whether they are published or not. The documents may come from teaching and research institutions in France or abroad, or from public or private research centers.
L'archive ouverte pluridisciplinaire HAL, est destinée au dépôt et à la diffusion de documents scientifiques de niveau recherche, publiés ou non, émanant des établissements d'enseignement et de recherche français ou étrangers, des laboratoires publics ou privés. 


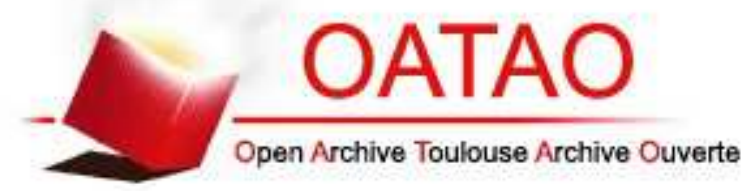

\section{Open Archive TOULOUSE Archive Ouverte (OATAO)}

OATAO is an open access repository that collects the work of Toulouse researchers and makes it freely available over the web where possible.

This is an author-deposited version published in : http://oatao.univ-toulouse.fr/ Eprints ID : 11997

To link to this article : doi:10.1016/j.rser.2014.07.138

URL : http://dx.doi.org/10.1016/j.rser.2014.07.138

To cite this version : Rigo-Mariani, Rémy and Sareni, Bruno and Roboam, Xavier and Turpin, Christophe Optimal power dispatching strategies in smart-microgrids with storage. (2014) Renewable and Sustainable Energy Reviews, vol. 40 . pp. 649-658. ISSN 13640321

Any correspondance concerning this service should be sent to the repository administrator: staff-oatao@ listes-diff.inp-toulouse.fr 


\title{
Optimal power dispatching strategies in smart-microgrids with storage
}

\author{
Rémy Rigo-Mariani*, Bruno Sareni, Xavier Roboam, Christophe Turpin \\ LAPLACE, UMR CNRS-INPT-UPS, ENSEEIHT, 2 Rue Camichel, 31071 Toulouse, France
}

Keywords:

Smart-grids

Optimal power dispatching

Trust region algorithm

Genetic algorithms

Particle swarm

Dynamic programming

\section{A B S T R A C T}

With the development of decentralized power sources based on renewable energy, power grids need smarter operations to be run properly. This paper investigates different procedures for the optimal power dispatching of a grid-connected prosumer with an energy storage consisting in a high speed flywheel. An off-line optimal scheduling for the day ahead aims at minimizing the cost with regards to the daily energy rates and considering the forecasts for both consumption and production. That dispatching is performed thanks to global optimization procedures based on a trust-region method or on a niching genetic algorithm. Another approach using step by step optimization and exploiting an original self-adaptive dynamic programming strategy is also developed. The paper discusses the performance of all the considered methods with regards to the obtained results and the computational time.

\section{Contents}

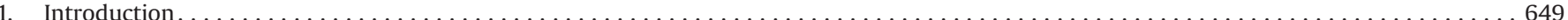

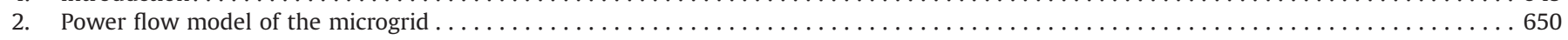

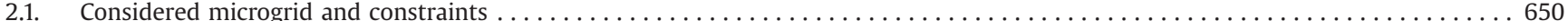

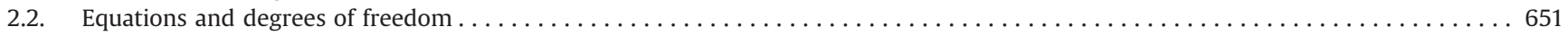

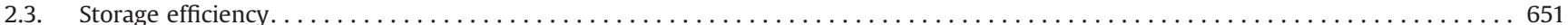

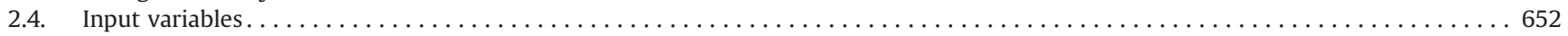

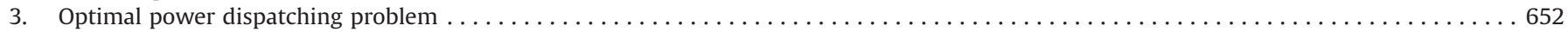

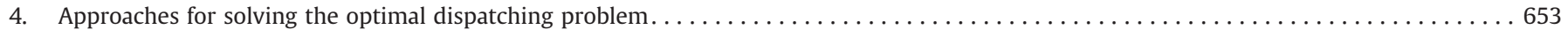

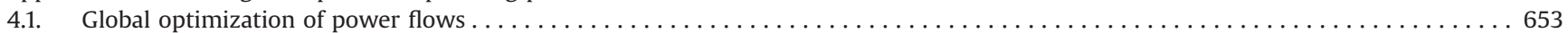

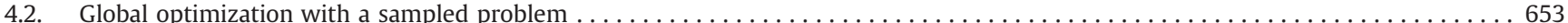

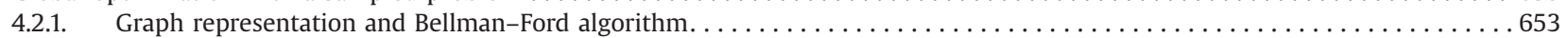

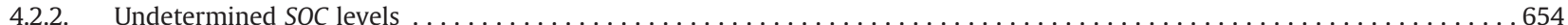

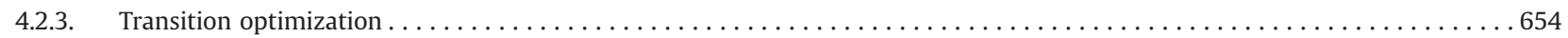

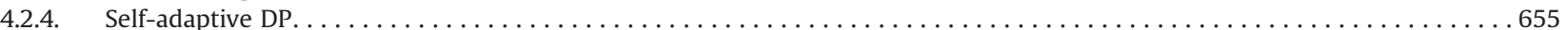

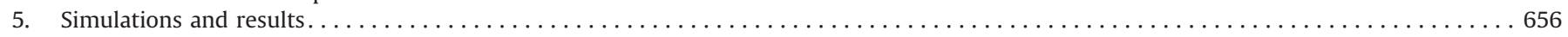

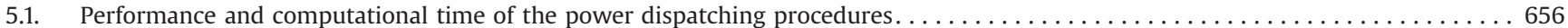

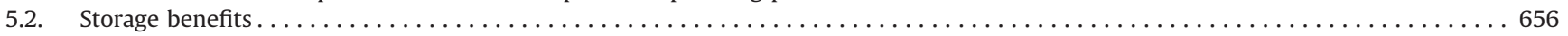

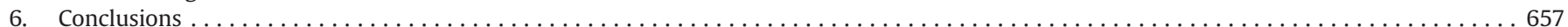

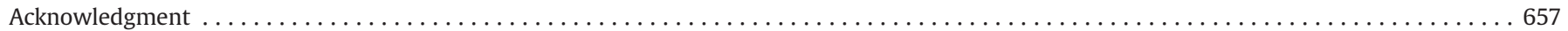

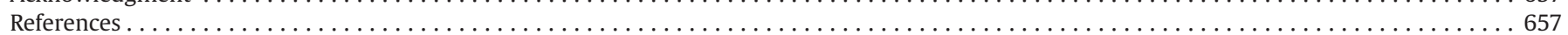

* Corresponding author: Tel.: +3353432 2356 .

E-mail address: remy.rigo-mariani@laplace.univ-tlse.fr (R. Rigo-Mariani).

\section{Introduction}

Global energy consumption has increased by $50 \%$ since the 90 's and is expected to keep going up with a ratio of $1.6 \%$ per year due to the growing population on earth and the new needs that have 
a

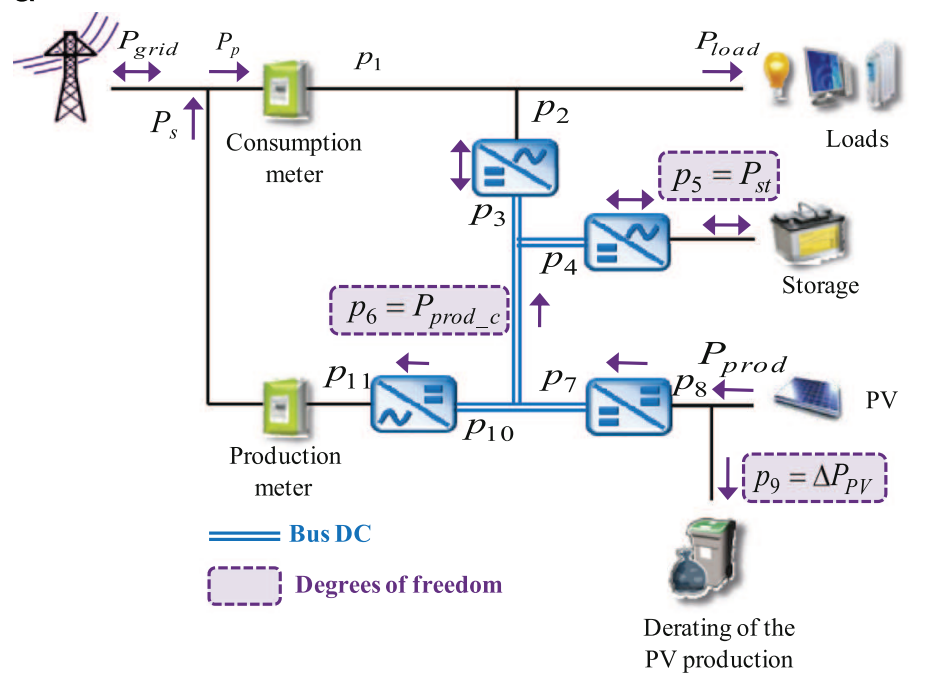

b

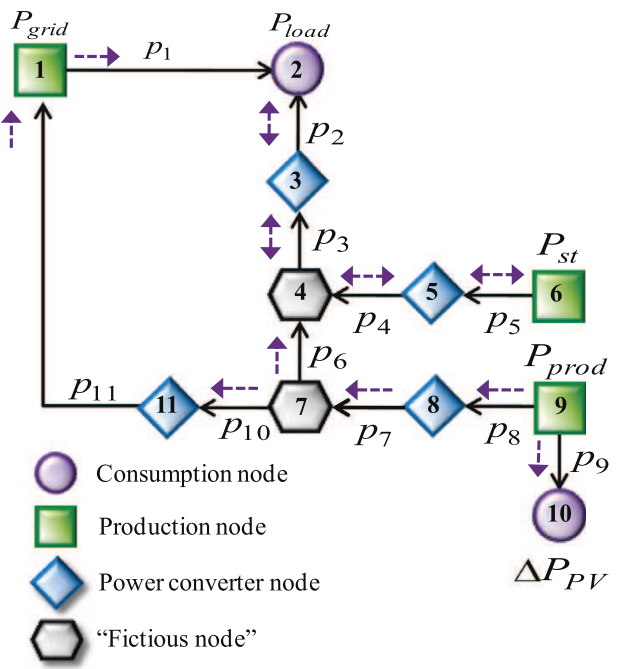

Fig. 1. Considered microgrid (a) and graph representation (b).

emerged [1]. To face that increasing demand of electrical power in compliance with the liberalization of the electricity market and the need of reducing $\mathrm{CO}_{2}$ emissions, many distributed energy resources have appeared and especially the generation systems that utilize renewable energy sources. Thus, distribution networks evolve towards more meshed structures, and they are likely to become associations of a large number of "microgrids" combining both consumption and production and interacting with the main grid [2]. Due to the stochastic nature of those generations, it requires smarter operations to keep feeding loads in a supply-ondemand system. The improvements in storage technologies allow those operations with a more flexible and reliable management of energy [3]. Renewable energy sources associated with storage units are then considered like active distributed generators, one of the fundamental elements of the "Smart Grid" concept [4]. Adding a storage device deeply questions the most widely used model that consists in selling all the highly subsidized production at important prices and buying the whole consumption. It also allows the owners of microgrids to optimize the power exchanged with the main grid in compliance with the electricity market and the forecasts for the day ahead [5]. Thus, more and more methods based on optimization algorithms are developed to perform the optimal scheduling of power flows within the hybrid electrical systems with load, production and storage [6,7]. In the microgrid considered in this study, all the components are connected through a DC bus (Fig. 1a) with the following data:

- Consumption: A building with a maximum contractual power of $156 \mathrm{~kW}$.

- Production: Solar PV arrays with a total capacity of $175 \mathrm{kWp}$.

- Storage: A $100 \mathrm{~kW} / 100 \mathrm{kWh}$ storage consisting in ten $10 \mathrm{~kW} /$ $10 \mathrm{kWh}$ high speed flywheels.

In this paper, an off-line optimal power dispatching problem is introduced with the aim of minimizing global energy cost, considering the forecasts for consumption and production and the possible constraints imposed by the main grid operator. The second section describes the power flow model used to represent the system and the corresponding equations. Then, the next part refers to the proposed optimization methods using an evolutionary algorithms or a trust region strategy that both consider the global load consumption and the PV production over the day. A step by step optimization based on basic Dynamic Programming
(DP) is also presented and an original self-adaptive DP is developed. Finally, some results performed with the various algorithms are exposed and discussed, especially in terms of reliability, efficiency and computational time.

\section{Power flow model of the microgrid}

\subsection{Considered microgrid and constraints}

Voltages and currents are not considered so far. The study refers to the optimization of active power flows $p_{i}$ which appear to be a widely used formulation for such a problem [8,9]. A nomenclature of all the used symbols is given in Table 1. Eleven power flows are identified to entirely characterize the system at each time step.

- $p_{1}$ : power flowing through the consumption meter

- $p_{2}$ : power flowing between the DC bus and the consumption branch after the converter

- $p_{3}$ : power flowing between the DC bus and the consumption branch before the converter

- $p_{4}$ : power flowing between the storage and the DC bus after the converter

- $p_{5}$ : power flowing between the storage and the DC bus before the converter

- $p_{6}$ : power flowing between the production branch and the rest of the DC bus

- $p_{7}$ : effective solar production after the converter

- $p_{8}$ : effective solar production before the converter

- $p_{9}$ : derating of the solar production in case of microgrid congestion (section 2.2)

- $p_{10}$ : power flowing through the production meter before the converter

- $p_{11}$ : effective production sold

Due to the grid policy, three system constraints have to be fulfilled at each time step $t$ :

- $P_{p}(t) \geq 0$ : the power cannot return to the grid through the consumption meter.

- $P_{S}(t) \geq 0$ : the main grid cannot feed the DC bus through the production meter. 
Table 1

Nomenclature of the used symbols.

\begin{tabular}{|c|c|c|}
\hline$P_{\text {load }}$ & Consumed power & $\mathrm{kW}$ \\
\hline$P_{\text {prod }}$ & solar PV production & $\mathrm{kW}$ \\
\hline$p_{i}$ & $\begin{array}{l}\text { power flows used to characterize the system (Section } \\
\text { 2.1) }\end{array}$ & $\mathrm{kW}$ \\
\hline$P_{p}$ & power flowing through the consumption meter & $\mathrm{kW}$ \\
\hline$P_{s}$ & power flowing through the production meter & $\mathrm{kW}$ \\
\hline$P_{s t}$ & power flowing from/to the storage unit & $\mathrm{kW}$ \\
\hline$P_{F S}$ & $\begin{array}{l}\text { power flowing from/to the flywheel taking account of } \\
\text { device losses }\end{array}$ & $\mathrm{kW}$ \\
\hline $\begin{array}{l}P_{\text {st_min }}, \\
P_{\text {st_max }}\end{array}$ & lower and upper bounds for $P_{s t}$ & $\mathrm{~kW}$ \\
\hline$E_{F S}$ & maximum stored energy in the storage unit & kWh \\
\hline$K_{F S}$ & self-discharge coefficient of the flywheels (Section 2.3) & $\begin{array}{l}\mathrm{kWh} / \\
\mathrm{h}\end{array}$ \\
\hline$\eta_{F S}$ & $\begin{array}{l}\text { flywheels efficiency depending on the exchanged power } \\
P_{s t}\end{array}$ & - \\
\hline SOC & state of charge of the storage unit & $\%$ \\
\hline $\begin{array}{l}S O C_{\min } \\
\quad S O C_{\max }\end{array}$ & lower and upper bounds for the $S O C$ level & $\%$ \\
\hline $\begin{array}{l}\mathrm{SOC}_{\text {start }} \\
\mathrm{SOC}_{\text {end }}\end{array}$ & initial and final daily values for the $S O C$ level & $\%$ \\
\hline$P_{\text {grid }}$ & power flowing between the main grid and the microgrid & $\mathrm{kW}$ \\
\hline $\begin{array}{l}\text { Prid_min } \\
\quad P_{\text {grid } \min }\end{array}$ & $\begin{array}{l}\text { lower and upper bounds for } P_{\text {grid }} \text { possibly set by the } \\
\text { power supplier }\end{array}$ & $\mathrm{kW}$ \\
\hline$\eta_{C V S, i}$ & $\begin{array}{l}\text { efficiency of the } i \text { th converter in the graph } \\
\text { representation (Fig. 1b) }\end{array}$ & - \\
\hline$\Delta P_{P V}^{-}$ & $\begin{array}{l}\text { solar production derated in case of microgrid congestion } \\
\text { (Section } 2.2 \text { ) }\end{array}$ & $\mathrm{kW}$ \\
\hline$C_{\text {purchase }}$ & instantaneous cost for the purchased energy & $€ / \mathrm{kWh}$ \\
\hline$C_{\text {sale }}$ & instantaneous cost for the sold energy & $€ / \mathrm{kWh}$ \\
\hline$t$ & time step & h \\
\hline $\mathbf{P}_{\text {ref }}$ & $\begin{array}{l}\text { matrix with the scheduled controls for the degrees of } \\
\text { freedom }\end{array}$ & $\mathrm{kW}$ \\
\hline$C\left(\mathbf{P}_{\text {ref }}\right)$ & $\begin{array}{l}\text { daily cost to be minimized by the optimization } \\
\text { algorithm }\end{array}$ & $€$ \\
\hline $\mathbf{C}_{\mathbf{n l}}$ & $\begin{array}{l}\text { vector with the non linear constraints of the } \\
\text { optimization problem }\end{array}$ & - \\
\hline
\end{tabular}

- $P_{\text {prod_c }}(t) \geq 0$ : the storage cannot be discharged through the production meter.

A particular attention is attached to the grid power $P_{\text {grid }}(t)$ which should comply with requirements possibly set by the grid operator $P_{\text {grid_min }}$ and $P_{\text {grid_max }}$ :

$$
\begin{aligned}
& P_{\text {grid }}(t)=P_{p}(t)-P_{S}(t) \\
& P_{\text {grid_min }}(t)<P_{\text {grid }}(t)<P_{\text {grid_max }}(t)
\end{aligned}
$$

\subsection{Equations and degrees of freedom}

Equations are generated using the graph theory and an incidence list to describe the system with particular equations corresponding to each type of node [10]. In Fig. 1b, the black arrows between nodes represent sign conventions for power flows while the possible directions (mono or bi-directional) are illustrated by the dotted arrows. Three degrees of freedom are required to control the whole system (Fig. 1a):

- $P_{s t}(\mathrm{t})$ : the power flowing from/to the storage unit

- $P_{\text {prod_c }}(t)$ : the power flowing from the solar PV arrays to the common DC bus

- $\Delta P_{P V}(t)$ : denotes the possibility to decrease the solar PV production (MPPT derating) in order to fulfill grid constraints, in particular when the power supplier does not allow (or limits) injection of the solar PV production to the main grid $\left(P_{\text {grid_min }}\right)$. For instance, if the flywheels are fully charged while production is greater than consumed energy and if no injection is allowed to the grid, a part of the produced energy should be wasted to fulfill the main grid constraints.

Those degrees of freedom being set from a management process, all power flows in the microgrid can be expressed from the consumption $P_{\text {load }}(t)$ and production $P_{\text {prod }}(t)$ and from the input data, i.e. $\eta_{C V S, i}$ (typically $\eta_{C v s, i}=95 \%$ ) the efficiency related to the power converter corresponding to the node $i$. From the graph representation, subsequent equations can be derived:

$p_{1}(t)=P_{\text {load }}(t)-p_{2}(t)$

$p_{2}(t)=p_{3}(t)+\left(1-\frac{1}{\eta_{C V S, 3}}\right) \cdot \max \left(0,-p_{3}(t)\right)+\left(\eta_{C V S, 3}-1\right) \cdot \max \left(0, p_{3}(t)\right)$

$p_{3}(t)=p_{4}(t)+p_{6}(t)$

$p_{4}(t)=p_{5}(t)+\left(1-\frac{1}{\eta_{C V S, 5}}\right) \cdot \max \left(0,-p_{5}(t)\right)+\left(\eta_{C V S, 5}-1\right) \cdot \max \left(0, p_{5}(t)\right)$

$p_{7}(t)=\eta_{C V S, 8} \cdot p_{8}(t)$

$p_{8}(t)=P_{\text {prod }}(t)-p_{9}(t)$

$p_{10}(t)=p_{7}(t)-p_{6}(t)$

$p_{11}(t)=\eta_{C V S, 11} \cdot p_{10}(t)$

Note that in (4) and (6) the power flows through converters are bidirectional. Two cases are identified depending on the direction of the flows to determine how the corresponding converter efficiency $\eta_{C V S, i}$ has to be considered. That is performed using the max function:

$\begin{cases}\max (a, b)=a & \text { if } a \geq b \\ \max (a, b)=b & \text { if } a<b\end{cases}$

The next sections only refer to the flows $P_{p}, P_{s}, P_{\text {grid }}$ and the degrees of freedom that are the truly interesting powers in term of management.

\subsection{Storage efficiency}

The storage losses are computed versus the state of charge SOC (in \%) and the power $P_{s t}$ using a function $P_{\text {loss }}(S O C)$ and calculating the efficiency with a fourth degree polynomial interpolation $\eta_{F S}\left(P_{S t}\right)$ as shown in (11). Interpolations are extracted from experimental measurements provided by the manufacturer. Note that due to confidentiality constraints, no additional information related to quantitative data have been allowed to be provided. Both $P_{\text {loss }}$ and $\eta_{F S}$ functions are also extracted from measurements provided by the manufacturer. Another coefficient $K_{F S}$ (in $\mathrm{kW}$ ) is also introduced to estimate the self-discharge of the flywheels when they are not used [11]. Once the overall efficiency is computed, the true power $P_{F S}$ associated with the flywheel is calculated as well as the SOC evolution using the maximum stored energy $E_{F S}$ (here $100 \mathrm{kWh}$ ), the time step $\Delta t$ (typically $1 \mathrm{~h}$ for the off-line optimization) and the control reference $p_{5}$.

$\left\{\begin{array}{l}P_{s t}(t)<0 \rightarrow P_{F S}(t)=P_{s t}(t) \times \eta_{F S}\left(-P_{s t}(t)\right) \\ P_{s t}(t)>0 \rightarrow P_{F S}(t)=P_{s t}(t) / \eta_{F S}\left(P_{s t}(t)\right)\end{array}\right.$

Thus, when a power $p_{5}$ is required from the storage (i.e. $p_{5}>0$ ), the actual power $P_{F S}$ including the flywheels losses is computed to estimate the loss of stored energy that have to be decreased to the discharge power. The same process is performed when $p_{5}$ becomes negative for storage charging. If no power flows from/to the flywheels, the loss of stored energy is limited to the self- 
a

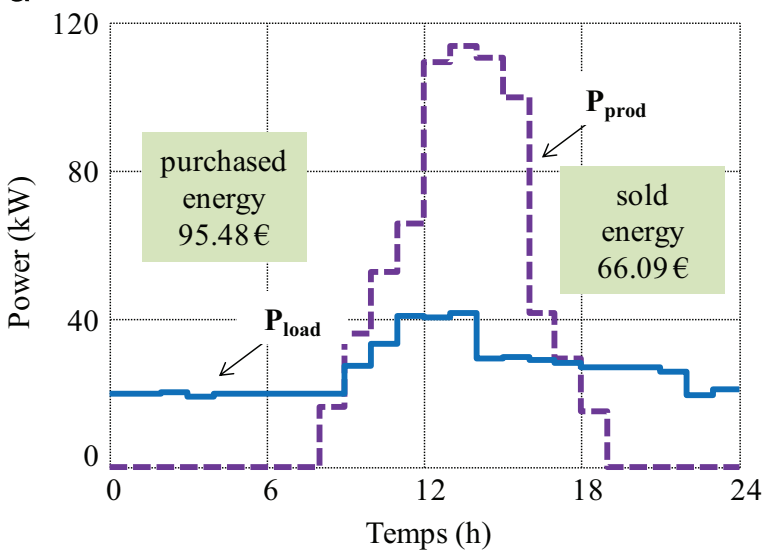

b

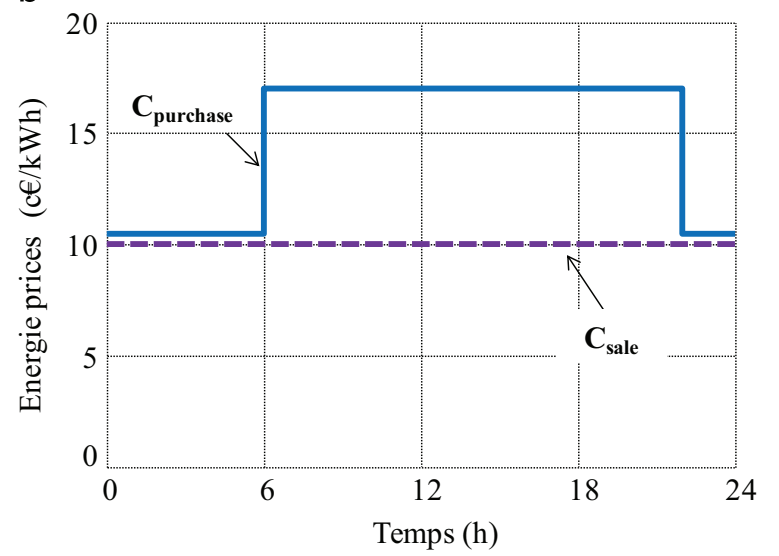

Fig. 2. Typical forecasted (a) consumption and production and (b) energy prices .

discharge coefficient:

$\left\{\begin{array}{l}P_{S t}(t) \neq 0 \rightarrow \operatorname{SOC}(t+\Delta t)=S O C(t)-\frac{P_{F S}(t) \times \Delta t}{E_{F S}} \times 100 \\ P_{S t}(t)=0 \rightarrow \operatorname{SOC}(t+\Delta t)=S O C(t)-\frac{K_{F S} \times \Delta t}{E_{F S}} \times 100\end{array}\right.$

The energy management strategy must ensure that both power and energy bounds are fulfilled with regards to storage power limits, i.e. $P_{\text {st_min }}=-100 \mathrm{~kW}$ and $P_{\text {st_max }}=100 \mathrm{~kW}$. With a storage assumed to be charged at $S O C_{\text {start }}=50 \%$ at the beginning of the day, the solving procedures should fulfill both upper and lower energy limits (i.e. $S O C_{\min }=0 \%$ and $S O C_{\max }=100 \%$ ) while ensuring a final value $S O C_{\text {end }}=50 \%$.

\subsection{Input variables}

The energy management strategy is based on consumption and production forecasts similar to the example depicted in Fig. 2a. The consumption profile is computed using measurements performed on the microgrid site and the production forecast uses a geophysical model considering among other the incidence and orientation of the solar PV arrays $[12,13]$ as well some estimation of the radiated energy on the microgrid site for the corresponding day.

The energy prices result from one of the fares proposed by the French main energy supplier. The purchase cost $C_{\text {purchase }}$ has night and daily values with $0.10 € / \mathrm{kWh}$ from $10 \mathrm{p} . \mathrm{m}$. to $6 \mathrm{a}$.m. and 0.17 $€ / \mathrm{kWh}$ for the other time steps. An average fare of $C_{\text {sale }}=0.10 € / \mathrm{kWh}$ is also considered for the production meter (Fig. 2b). Finally, an additional grid power constraints is introduced with $P_{\text {grid_- }}$ $\max =0 \mathrm{~kW}$ between 7 p.m. and 10 p.m. with the aim of imposing the microgrid autonomous operation during this period. Otherwise the bounds are set to high values (typically $10^{3} \mathrm{~kW}$ ). Without storage device and optimal management, all the consumption is purchased from the grid while the PV production is sold. The resulting cost for that initial situation (noted Init) is $28.39 €$. If the self-consumption of the production is considered, the generated energy feds the loads and the surplus is sold. In that case (noted SelfCons) the overall cost is of $5.82 €$. Note that in both situations the previous grid constraints cannot be fulfilled by the microgrid.

\section{Optimal power dispatching problem}

The problem consists in planning, for each hour of a $24 \mathrm{~h}$ period, the best power dispatching that ensures the minimal energy cost of the microgrid while complying with the grid requirements. The decision variables computed in a vector $\mathbf{P}_{\text {ref }}$ are the degrees of freedom defined in the previous section according to upper and lower bounds respectively computed in vectors $\mathbf{u}_{\mathbf{b}}$ and $\mathbf{l}_{\mathbf{b}}$. Those bounds can be expressed using a vector $\mathbf{J}_{\mathbf{2 4}}$ composed of 24 values equal to one. With a time step of $1 \mathrm{~h}$, the total number of decision variables is 72 .

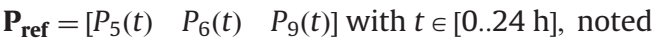

$\mathbf{P}=\left[\begin{array}{lll}\mathbf{P}_{5} & \mathbf{P}_{6} & \Delta \mathbf{P}_{9}\end{array}\right]$

$\mathbf{l}_{\mathbf{b}}=\left[\begin{array}{lll}P_{\text {st_min }} \cdot \mathbf{J}_{24} & 0 . \mathbf{J}_{24} & 0 . \mathbf{J}_{24}\end{array}\right]$

$\mathbf{u}_{\mathbf{b}}=\left[P_{\text {st_max }} \cdot \mathbf{J}_{24} \eta_{C V S, 8} \cdot P_{\text {prod }} P_{\text {prod }}\right]$

The overall cost to be optimized is the difference between the sold and purchased energies during the day obtained by calculating the flows $P_{p}$ and $P_{s}$ all along the simulated period (typically $24 \mathrm{~h}$ ) for a set of parameters $\mathbf{P}_{\text {ref: }}$ :

$C\left(\mathbf{P}_{\text {ref }}\right)=\sum_{t=0}^{24} C_{\text {purchase }}(t) \cdot P_{p}(t)-C_{\text {sale }} \cdot P_{s}(t)$ with $\Delta t=1 \mathrm{~h}$

Some constraints in the microgrid are implicitly included in the bounds previously defined. Additional constraints are added in order to fulfill all power flow requirements defined in Section 2. Eq. (16) allows controlling the powers though the meters that have both to remain positive with the given convention and set the two corresponding constraints $C P_{p}$ and $C P_{s}$.

$\left\{\begin{array}{l}C P_{p}=\sum_{t=0}^{24 h} \max \left(0,-P_{p}(t)\right)^{2} \\ C P_{S}=\sum_{t=0}^{24 h} \max \left(0,-P_{s}(t)\right)^{2}\end{array}\right.$

The possible bounds set by the grid operator for $P_{\text {grid }}$ are considered by summing all the overshoots. The negative and positive deviations are computed in constraints $C P_{\text {grid }}^{-}$and $C P_{\text {grid. }}^{+}$.

$\left\{\begin{array}{l}C P_{\text {grid }}^{+}=\sum_{t=0}^{24 h} \max \left(0, P_{\text {grid }}(t)-P_{\text {grid_max }}(t)\right)^{2} \\ C P_{\text {grid }}^{-}=\sum_{t=0}^{24 h} \max \left(0, P_{\text {grid_ } \min }(t)-P_{\text {grid }}(t)\right)^{2}\end{array}\right.$

The three last limits refer to the use of the storage unit. Indeed the SOC has to remain between its lower and upper bounds and return at a given value at the end of the day (i.e. $t=24 \mathrm{~h}$ ). The corresponding constraints are noted $\mathrm{CSOC}^{-}, \mathrm{CSOC}^{+}$and $\mathrm{CSOC}_{\text {end }}$.

$$
\left\{\begin{array}{l}
\mathrm{CSOC}_{\text {end }}=\operatorname{SOC}(24 h)-S O C_{\text {end }} \\
\mathrm{CSOC}^{+}=\sum_{t=0}^{24 h} \max \left(0, S O C(t)-S O C_{\max }\right)^{2} \\
\mathrm{CSOC}^{-}=\sum_{t=0}^{24 h} \max \left(0, S O C_{\min }-S O C(t)\right)^{2}
\end{array}\right.
$$


All those constraints are strongly nonlinear due to the bidirectional characteristic of static converters and the flywheel efficiency. They are computed in a vector $\boldsymbol{C}_{\mathbf{n}}$ that will be used in the algorithms developed to optimize the energy management.

$\mathbf{C}_{\mathbf{n l}}=\left[\begin{array}{llllll}C P_{p} & \mathrm{CSOC}^{-} & \mathrm{CSOC}^{+} & \mathrm{CSOC}_{\text {end }} & \mathrm{CP}_{\text {grid }}^{+} & \mathrm{CP}_{\text {grid }}^{-}\end{array}\right]$

For all the constraints (except $C S O C_{\text {end }}$ ), the returned value is computed as the sum of the instantaneous violations determined with the max function all along the day. For instance, considering (16), if $P_{s}(\mathrm{t})$ is negative, the instantaneous violation is expressed as the square value of the power flow. Then, the overall corresponding constraint for the dispatching problem is the sum of all overshoots. The final optimal dispatching problem consisting in managing the power flows for the day ahead with $1 \mathrm{~h}$ of time step could be considered as a long term scheduling. In real time, a short term scheduling (with a shorter sampling period) has to be run to take account of the differences between the actual values and the forecasts for the production and consumption [14]. At a lower level, an efficient control loop has to be implemented to manage the current/voltage references for the different converters according to the values returned by the short term scheduling. Those two last problems are not the aim of the paper but are crucial in the field of smart microgrids [15].

\section{Approaches for solving the optimal dispatching problem}

\subsection{Global optimization of power flows}

The optimal dispatching in microgrids could be solved using step by step decisions with rules based methods such as state machine or fuzzy logic $[16,17]$. A great part of studies referring to scheduling in such systems use algorithms that consider the whole profiles and perform the global optimization of the mission for the entire time horizon (here $24 \mathrm{~h}$ ). For instance, linear programming is often performed to control of the system on a large time scale $[9,18]$. In this paper, three procedures are firstly investigated to manage optimal scheduling considering the mission all along the day.

The first optimization approach is a trust-region-reflective algorithm [19]. That method aims at solving the problem by approximating the objective function with a simpler quadratic function in a trust-region area. From an initial starting solution, the algorithm minimizes the cost while fulfilling all constraints and returns the best solution $\boldsymbol{P}_{\text {ref }}^{*}$ within the predefined bounds:

$\mathbf{P}_{\text {ref }}^{*}=\left[\begin{array}{lll}\mathbf{P}_{\mathbf{s t}}^{*} & \mathbf{P}_{\text {prod_c } c}^{*} & \Delta \mathbf{P}_{\mathbf{P V}}^{*}\end{array}\right]=\underset{\mathbf{P}_{\text {ref }}}{\arg \min }\left(C\left(\mathbf{P}_{\text {ref }}\right)\right)$ with $\quad \mathbf{C}_{\mathbf{n l}} \leq 0$

The second method uses the clearing algorithm [20] a niching genetic algorithm which preserves diversity in the population in order to avoid premature convergence. The particle swarm optimization method [21] is lastly used to solve the power management scheduling [22]. For those metaheuristics, all constraints related to power flows are included in the cost function with a classical exterior penalty approach. The algorithm returns the best individual in the population (or in the particle swarm) from a given number of iterations:

$\mathbf{P}_{\text {ref }}^{*}=\left[\begin{array}{lll}\mathbf{P}_{\mathbf{s t}}^{*} & \mathbf{P}_{\text {prod_c }}^{*} & \Delta \mathbf{P}_{\mathbf{P V}}^{*}\end{array}\right]=\underset{\mathbf{P}_{\text {ref }}^{*}}{\arg \min }\left(C\left(\mathbf{P}_{\text {ref }}\right)+\lambda \cdot \sum_{i} \mathbf{C}_{\mathbf{n l}}(i)\right)$

where the penalty coefficient $\lambda$ is set to $10^{6}$ to ensure the constraints fulfilment.

\subsection{Global optimization with a sampled problem}

\subsubsection{Graph representation and Bellman-Ford algorithm}

Just like the three methods previously exposed, the approach presented in this section optimizes the whole mission (i.e. the references for the degrees of freedom for the whole day). The problem is here represented as a succession of possible discrete states characterized by a time position $t$ over one day and a state of charge $S O C$ [23] as shown in Fig. 3a. With both $S O C_{\text {start }}$ and $S O C_{\text {end }}$ fixed in the problem there is only one available state for the initial and final time step. The mix of individual states taken for each time step returns a SOC profile all along the day that corresponds to a given solution $\boldsymbol{P}_{\text {ref }}$ computed with all the instantaneous controls ensuring transitions between the selected states. Finding the best solution $\boldsymbol{P}_{\text {ref }}^{*}$ is equivalent to estimating the shortest path in terms of cost from the initial state to the final one. That is the base of the Dynamic Programming (DP) approach as developed here.

The cost of a solution equals to the sum of all the individual costs referring to the transitions between states. Thus, the Dynamic Programming requires computing all the transitions between the states situated at two successive time step (Fig. 3b). Transition are studied with regard to the instantaneous cost that depends on the values of the consumption and production as well as the instantaneous references of the degrees of freedom. The estimated cost of a transition is optimized as explained in Section 4.2.3. This cost is highly penalized if the corresponding transition appears to be infeasible due to the non-fulfilment of the system constraints (e.g. non fulfilment of the bounds associated with the main grid power $\left.P_{\text {grid }}\right)$.

Once all transitions are studied, it is possible to determine the shortest path (i.e. the lowest cost) that allows reaching a state $M$ starting from the initial point $M_{0}$. At the previous time step, the obtained shortest path goes through the "predecessor" of $M$ and denoted as $M^{\prime}$ (Fig. 4a). The predecessors of all the states are then determined moving forward for successive time steps. When all the predecessors are known, the optimal path is rebuilt backward from the final state using the Bellman-Ford algorithm [24] (Fig. 4b). The returned solution $\boldsymbol{P}_{\text {ref }}^{*}$ is the concatenation of all a

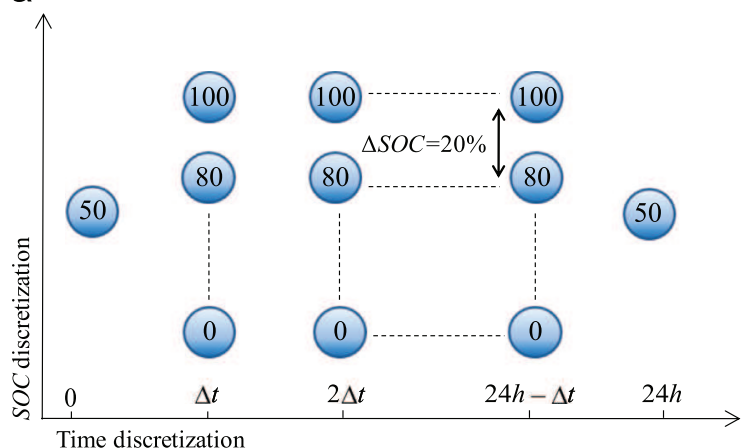

b

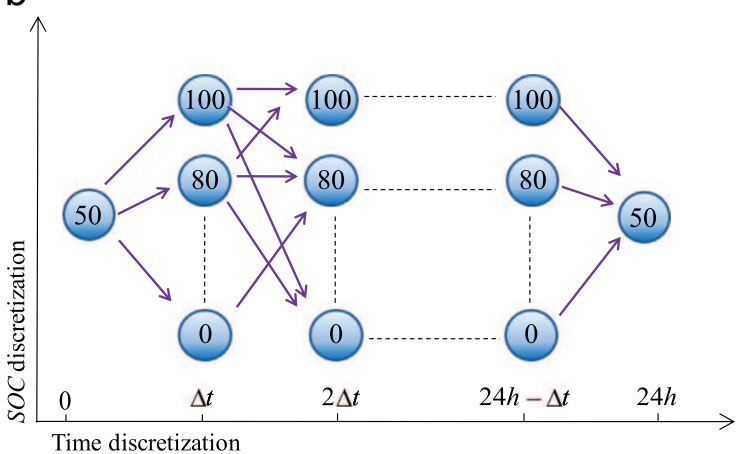

Fig. 3. Dynamic Programming - (a) sampling of the problem and (b) cost calculation. 
a

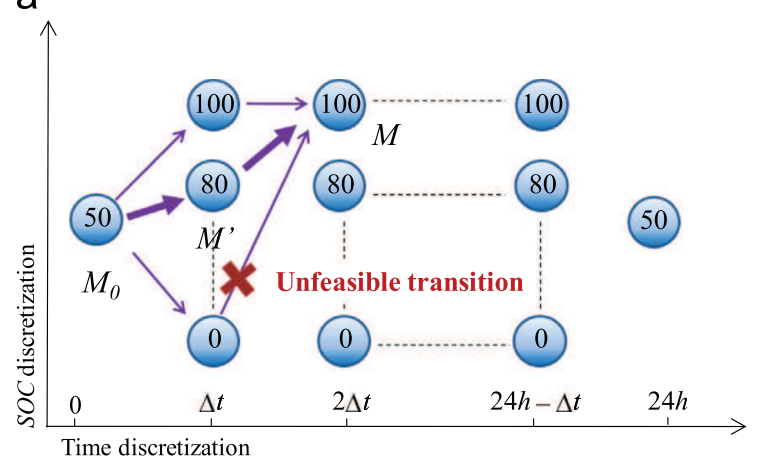

b

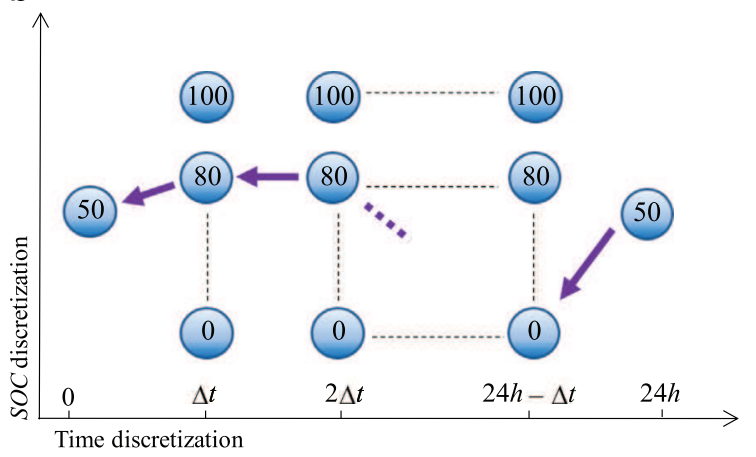

Fig. 4. Dynamic Programming - (a) Computation of the predecessors and (b) optimal path rebuilt.

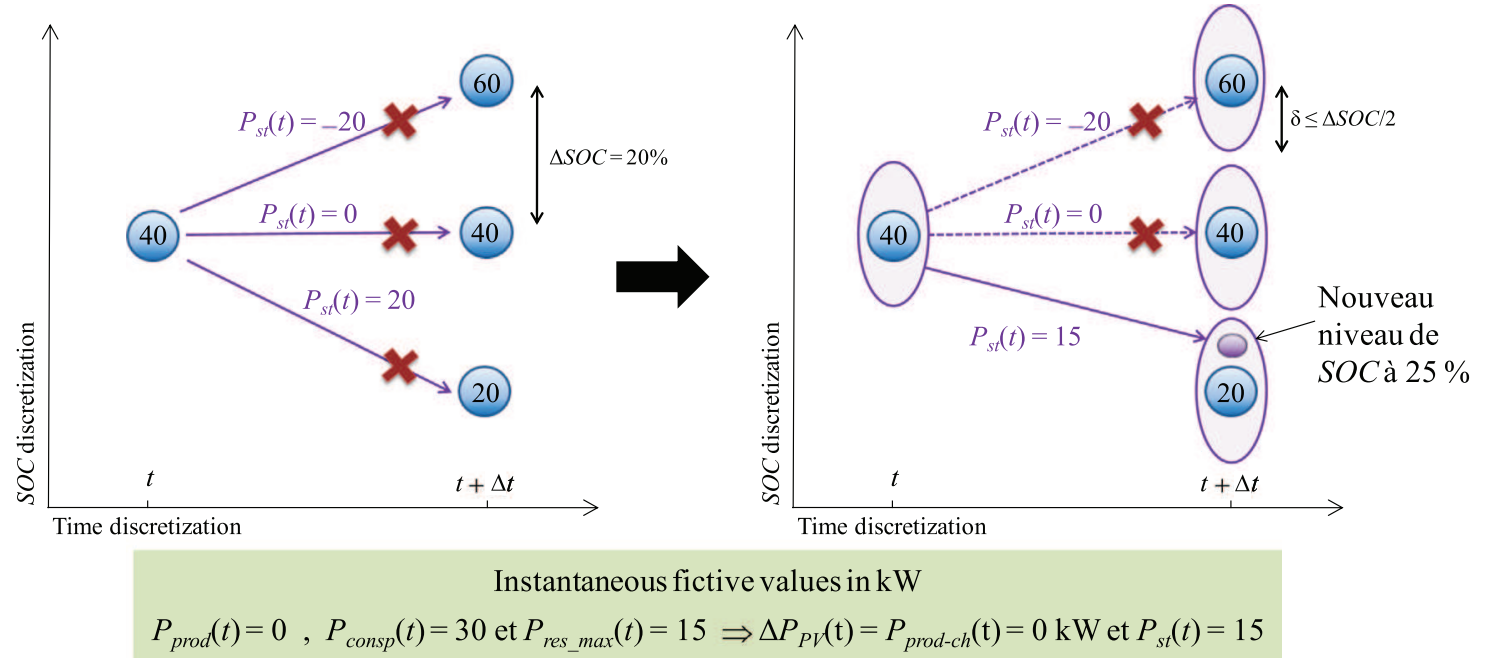

Fig. 5. Towards undetermined SOC levels.

the instantaneous controls of the power flows which relate to the degrees of freedom that allow to follow the optimal path.

\subsubsection{Undetermined SOC levels}

Moving from one SOC level to another consists in finding the best instantaneous degrees of freedom $P_{s t}(t), P_{\text {prod_c }}(t)$ and $\Delta P_{P V}(t)$ that ensure the transition with the lowest cost. Note that a transition between two pre-determined states of charge implicitly imposes the power value flowing through the storage unit $P_{\mathrm{st}}(t)$. However, in some cases, this can lead to the non-fulfilment of the grid constraints and the impossibility to ensure the transition. The resulting cost would be would be penalized. Fig. 5 illustrates a case with fictive values without considering losses. In this example, there is no production and the grid operator imposes a consumption to a given value $P_{\text {grid }}(t)$ different from $P_{\text {load }}(t)$. Thus $P_{\text {prod_c }}(t)=$ $\Delta P_{P V}(t)=0$ and then $P_{s t}(t)$ should fed the difference $P_{\text {grid }}(t)$ $P_{\text {load }}(t)$. That value does not necessary comply with the transition between two predetermined states of charge and a non convergence of the algorithm could occur.

The previous algorithm is then modified with the aim of relieving the storage constraints by considering a space search $\pm \delta$ around a predetermined SOC. The initial value of $\delta$ is set to $\Delta S O C / 2$ and is progressively reduced in case of non-convergence (typically $\delta \leftarrow \delta / 2$ ). In the example given in Fig. 5, moving towards undetermined SOC levels allows ensuring the transition starting from a SOC equal to $40 \%$ and could avoid a non convergence of the overall Dynamic Programming algorithm.

\subsubsection{Transition optimization}

As already said, studying a transition between two states $M$ and $M^{\prime}$ consists in minimizing the cost while adapting the state of charge for the next time step. This is performed using the trust region algorithm with a simpler problem than in the case with the global dispatching in so far as the number of decision variables simply equals here the number of degrees of freedom (i.e., three in the studied case). The bounds associated with the degrees of freedom as well as the grid constraints are expressed using the instantaneous values of the consumption and production. The storage constraints defined in (18) are modified in order to comply with the studied transition and adapt the SOC at the following state with $S O C^{\prime} \pm \delta$ :

$$
\begin{aligned}
& \operatorname{CSOC}^{+}(t)=\max \left(0, \operatorname{SOC}(t+\Delta t)-\operatorname{SOC}^{\prime}+\delta\right) \\
& \operatorname{CSOC}^{-}(t)=\max \left(0,-\operatorname{SOC}^{\prime}-\delta-\operatorname{SOC}(t+\Delta t)\right)
\end{aligned}
$$

Finally, the local optimal dispatching problem to be solved at each time step can be expressed as:

$$
\begin{aligned}
& \mathbf{P}_{\text {ref }}(t)=\left[P_{s t}(t) \quad P_{\text {prod_c }}(t) \quad \Delta P_{P V}(t)\right] \\
& \mathbf{l b}=\left[\begin{array}{lll}
P_{\text {st_min }} & 0 & 0
\end{array}\right] \\
& \mathbf{u b}=\left[\begin{array}{lll}
P_{\text {st_max }} & \eta_{\text {CVS }, 8} \cdot P_{\text {prod }}(t) & P_{\text {prod }}(t)
\end{array}\right] \\
& \mathbf{P}_{\text {ref }}^{*}(t)=\left[P_{s t}^{*}(t) P_{\text {prod_c }}^{*}(t) \Delta P_{P V}^{*}(t)\right]=\underset{\mathbf{P}_{\text {ref }}(t)}{\operatorname{argmin}}\left(C_{\text {purchase }}(t) \cdot P_{a}(t)-C_{\text {sale }}(t) \cdot P_{s}(t)\right) \\
& \text { with } \mathbf{C}_{\mathbf{n l}}^{\mathbf{t}}\left(\mathbf{P}_{\text {ref }}(t)\right)=\left[\begin{array}{llll}
C P_{a}(t) & C P_{S}(t) & \operatorname{CSOC}^{+}(t) & \operatorname{CSOC}^{-}(t)
\end{array}\right. \\
& \left.\times C P_{\text {grid }}^{-}(t) \quad C P_{\text {grid }}^{+}(t)\right] \leq 0
\end{aligned}
$$


a

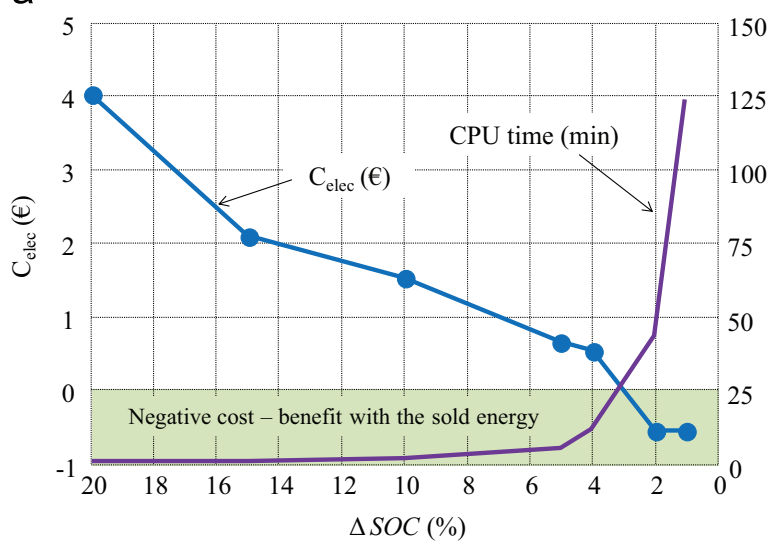

b

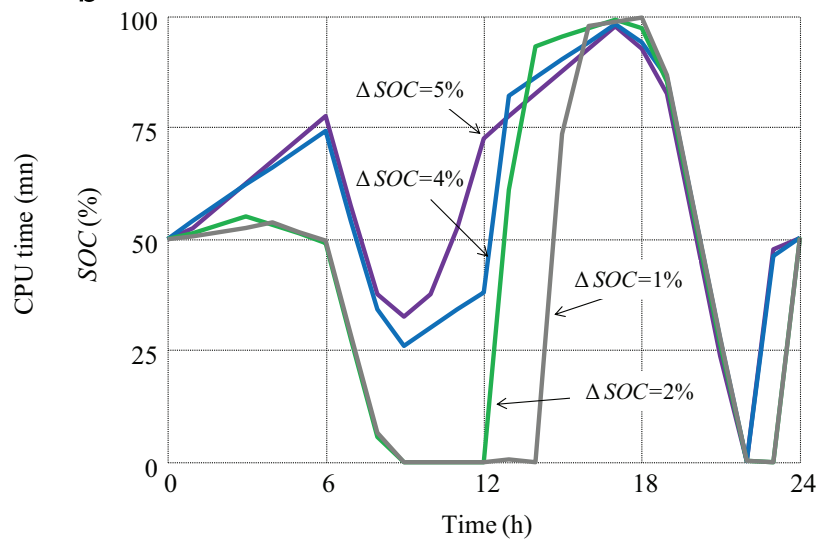

Fig. 6. DP results for different SOC level of accuracy: (a) Cost and CPU time - (b) Storage energy.

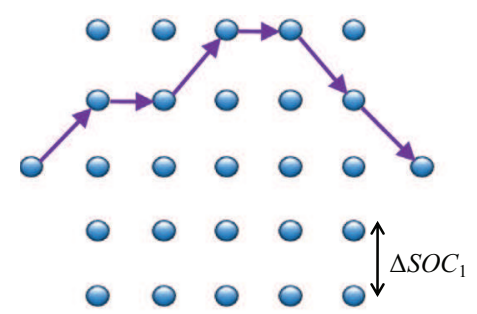

Step 1: Corse DP run with a large $\triangle S O C$ sampling value

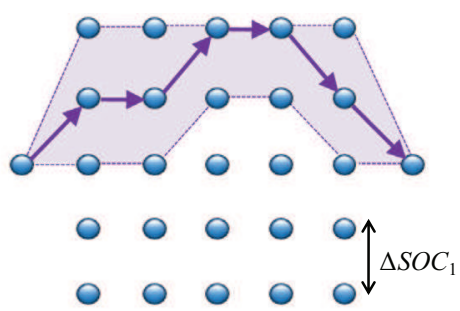

Step 2: Space search and number of states reduction

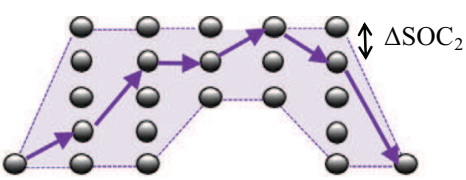

Step 3:New DP run with a smaller SOC sampling on the reduced area $\left(\triangle S O C_{2}=\triangle \mathrm{S} O C_{1} / 2\right)$

Fig. 7. Illustration of the self-adaptive Dynamic Programming.

Table 2

Performance of the trust-region reflective algorithm on the dispatching problem.

\begin{tabular}{|c|c|c|c|c|}
\hline & $P_{\text {refo }}^{1}$ & $P_{\text {refo }}^{2}$ & $P_{\text {refo }}^{3}$ & $P_{\text {refo }}^{4}$ \\
\hline Starting point & {$\left[\boldsymbol{P}_{\text {load }} \boldsymbol{P}_{\text {prod }} \boldsymbol{P}_{\text {prod }}\right]$} & {$\left[\begin{array}{lll}\boldsymbol{P}_{\text {load }} & 0 . J_{24} & 0 . J_{24}\end{array}\right]$} & {$\left[\begin{array}{llll}0 . J_{24} & 0 . J_{24} & 0 . J_{24}\end{array}\right]$} & {$\left[0 . J_{24} P_{\text {prod }} 0 \cdot J_{\mathbf{2 4}}\right.$} \\
\hline Convergence & no & yes & no & yes \\
\hline $\mathrm{C}\left(\mathrm{P}_{\mathrm{ref}}^{*}\right)($ in $€)$ & $x$ & 4.09 & $x$ & 6.63 \\
\hline CPU time & $33 s$ & $24 \mathrm{~s}$ & $1 \mathrm{~s}$ & $16 \mathrm{~s}$ \\
\hline
\end{tabular}

Table 3

Performance of the clearing algorithm on the dispatching problem.

\begin{tabular}{lllll}
\hline Number of generations & 1000 & 5000 & 10,000 & 50,000 \\
\hline Cost - Average Values $(€)$ & $3.80 \pm 1.08$ & $1.62 \pm 0.95$ & $1.25 \pm 0.81$ & $0.96 \pm 0.52$ \\
Cost best values $(€)$ & 2.53 & 1.11 & 0.79 & $0.87 \pm 0.38$ \\
Average CPU Time $(\mathrm{s})$ & $6 \mathrm{~min}$ & $35 \mathrm{~min}$ & $1 \mathrm{~h} 10 \mathrm{~min}$ & 0.66 \\
\hline
\end{tabular}

Table 4

Performance of the particle swarm algorithm on the dispatching problem.

\begin{tabular}{lllll}
\hline Number of Generations & 1000 & 5000 & 10,000 & 25,000 \\
\hline Cost -Average Values $(€)$ & $23.63 \pm 23.96$ & $19.04 \pm 19.51$ & $18.79 \pm 19.89$ & $17.86 \pm 19.75$ \\
Cost - best values $(€)$ & 9.35 & 6.48 & 4.99 & $17.80 \pm 19.81$ \\
Average CPU Time $(s)$ & $3 \mathrm{~min}$ & $15 \mathrm{~min}$ & $30 \mathrm{~min}$ & 4.90 \\
\hline
\end{tabular}

\subsubsection{Self-adaptive DP}

The DP returns good solutions but some preliminary results shows that its efficiency and convergence strongly depends on $\triangle S O C$ and $\delta$. As shown in Fig. $6 a$, the cost is improved with the reduction of $\triangle S O C$ while the computational time required to obtain the optimal solution is drastically increased. Note that the trajectories obtained for different values of $\triangle S O C$ shows the same energy balance of the storage which is discharged at the beginning 
of the day. Then the SOC increases when there is a great amount of solar production during the day. From 7 p.m. to 9 p.m., the flywheels are used to fulfill the grid constraints before returning to the desired state of charge at the end of the day. That optimal energetic behavior is found with great $\triangle S O C$. Indeed, decreasing the discretization allows reducing the cost by optimizing the losses within the elements of the microgrid.

In order to get the best solution corresponding to the finest $S O C$ sampling without a prohibitive CPU time, a self-adaptive DP (SDP) has been developed. At first, a basic DP is performed with a coarse $\triangle S O C$. Then, a space search is defined around the obtained solution meaning that the number of possible states is reduced around the optimal profile. Afterwards, a new DP is computed considering the reduced search space with a smaller $\triangle S O C$. As illustrated in Fig. 7, the selfadaptive DP consists in a succession of basic DP optimizations starting with a large $\triangle S O C$ and decreasing it to smaller values. At each iteration, the search space is reduced by considering a new area around the optimal path. Then, this area is refined by discretizing it with a smaller value of $\triangle S O C$ (typically $\triangle S O C=\Delta S O C / 2$ ).

\section{Simulations and results}

5.1. Performance and computational time of the power dispatching procedures

In this section, the results obtained with the different procedures are compared with regard to the cost function value and the

Table 5

Results obtained with the basic and self-adaptive DP.

\begin{tabular}{llllllll}
\hline$\Delta$ SOC & $20 \%$ & $15 \%$ & $10 \%$ & $5 \%$ & $2 \%$ & $1 \%$ & SDP \\
\hline Cost $(€)$ & 4.02 & 2.09 & 1.52 & 0.64 & -0.56 & -0.65 & -0.17 \\
CPU time & $30 \mathrm{~s}$ & $50 \mathrm{~s}$ & $1 \mathrm{~min} 30 \mathrm{~s}$ & $5 \mathrm{~min}$ & $45 \mathrm{~min}$ & $2 \mathrm{~h} 15 \mathrm{~min}$ & $10 \mathrm{~min}$ \\
\hline
\end{tabular}

Table 6

Costs analysis for different cases.

\begin{tabular}{llll}
\hline & Init & SeflCon & $\boldsymbol{P}_{\text {refSPD }}$ \\
\hline Purchased energy $(€)$ & 95.48 & 39.18 & 23.43 \\
Sold energy $(€)$ & 66.09 & 33.36 & 25.60 \\
Constraint fulfillment & no & no & yes \\
TOTAL $(€)$ & 28.39 & 5.82 & -0.17 \\
\hline
\end{tabular}

a

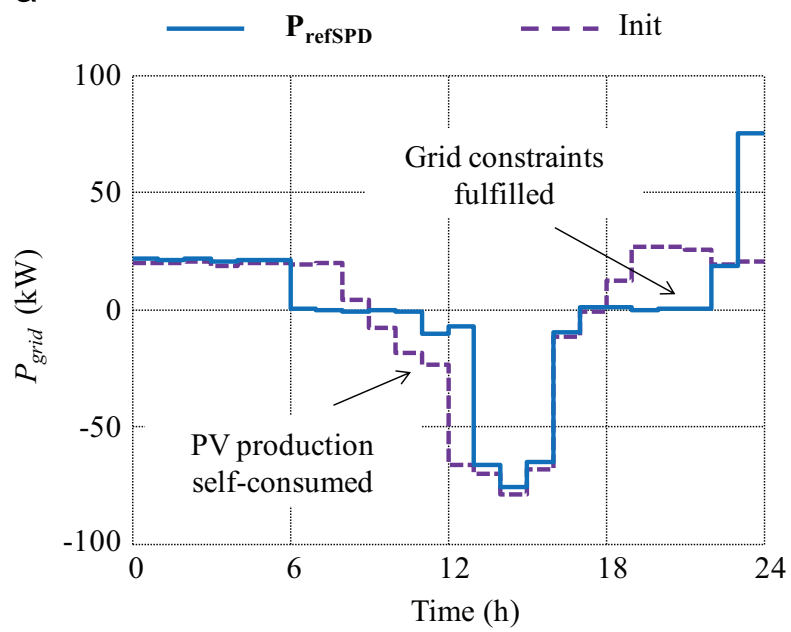

computational time. All tests are performed by considering a time step of $1 \mathrm{~h}$ and with the production and consumption profiles defined in Section 2. Table 1 shows the outputs of the trust region reflective algorithm with a maximum number of iterations equal to 150 . Four starting points $\boldsymbol{P}_{\text {refo }}^{\mathbf{i}}$ are considered. They do not necessarily fulfill the constraints and correspond to various assumptions such as providing all the consumption though the storage for instance. The convergence only occurs in half of the cases and the obtained results depend on the starting points (Table 2).

Tables 3 and 4 show the best results obtained by the nature inspired metaheuristics (i.e. clearing and PSO) after 10 independent runs. Average values with $95 \%$ level of confidence as well as the best results are presented. Performances become greater with high numbers of generations with a population size equal to 100 elements in the two algorithms. Both strategies are more reliable than the trust-region method with better accuracy for the genetic algorithm but their CPU time up to $2 \mathrm{~h}$ is rather expensive.

The self-adaptive DP gives the best results with a good accuracy and a reduced computational time (Table 5). A solution with accuracy of $\triangle S O C=1 \%$ is finally reached after 10 min instead of $2 \mathrm{~h}$ with the basic DP. It should be noted that the small deviation on the cost between the basic DP with $\Delta S O C=1 \%$ and the selfadaptive DP can be explained by different optimal paths found due to distinct values of $\delta$ around SOC levels during the search.

\subsection{Storage benefits}

Performance is now studied with regard to the optimal power profiles found with the solution returned by the SDP and noted

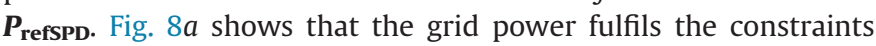
between 7 p.m. and 9 p.m. The storage is discharged at the beginning of the day in order o lower the cost when prices are higher (after 6 a.m.). Then the solar production feds the loads and charges the flywheels. At the end of the day the storage is fully used to satisfy the constraints before returned to the desired value $S C_{\text {end }}$ (Fig. 8b).

The optimal power sharing obtained with the SPD is illustrated in Fig. 9 with few of energy purchased from the grid during the daily hours. The high amount of PV production is self-consumed in the loads and the storage. The surplus is even sold to the grid to get an additional benefit with a negative final electrical bill $\left(C_{\text {elec }}\left(\boldsymbol{P}_{\text {refsDP }}\right)=-0.17 €\right)$.

b

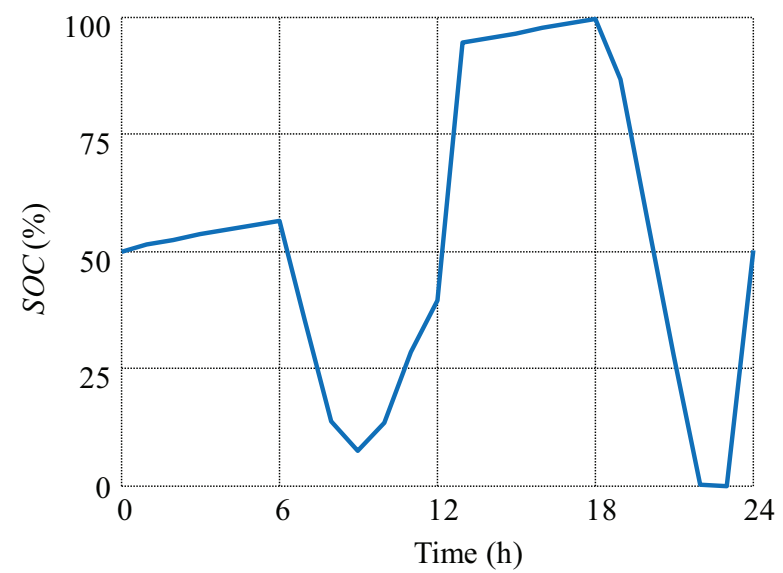

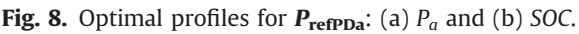


a

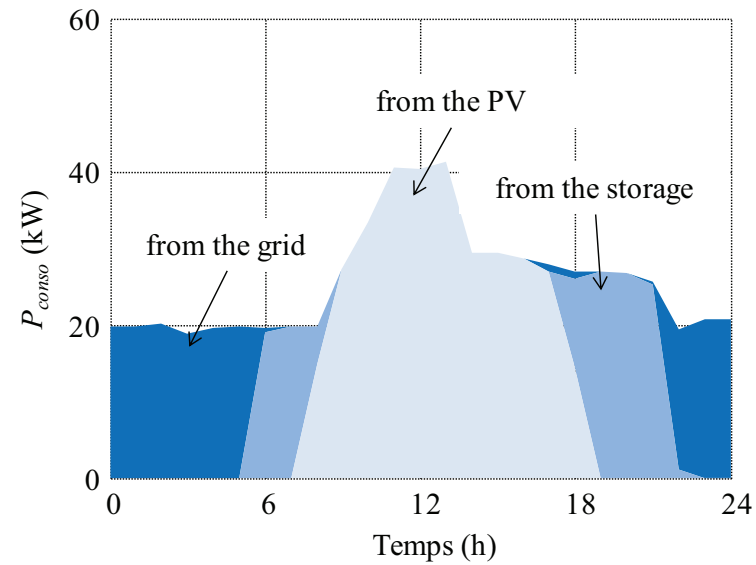

b

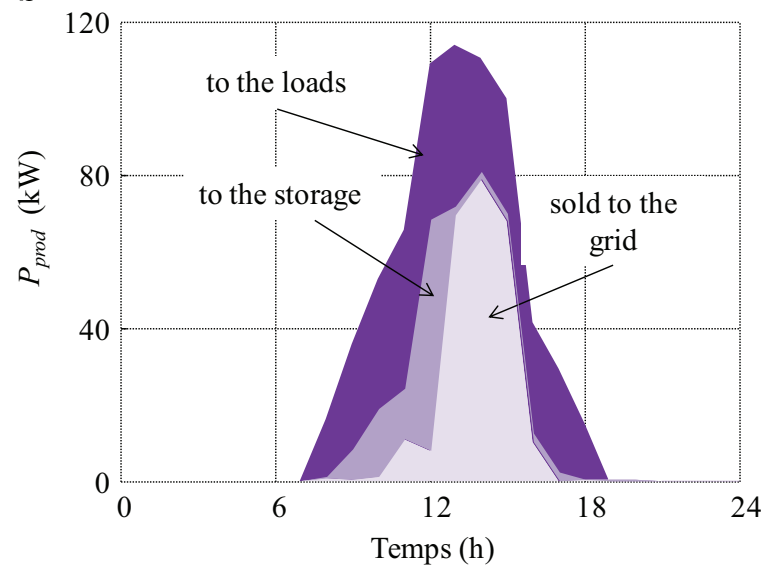

Fig. 9. Optimal power sharing with SPD - (a) Power flowing to the loads (b) powers flowing from the PV panels.

The cost analysis of the solution $\boldsymbol{P}_{\text {refsDp }}$ is now compared with the electrical bills corresponding to the cases Init and SelfCon. The best cost corresponds to a case with storage and optimal management (Table 6). Less production is sold but the self-consumption allows reducing the bill by lowering the purchased energy when prices are higher. Note that with no storage the grid constraints cannot be fulfilled. This could lead to pay additional penalties to the grid operator. On the contrary encouraging the constraints fulfillment with additional benefit could allow justifying the implementation of a storage unit whose cost has not been considered so far in the study.

\section{Conclusions}

In this paper, various optimization approaches have been compared in order to perform the optimal dispatching of power flows in a grid connected smart system involving loads, decentralized sources of renewable energy (solar PV panels) and flywheels as storage unit. In particular, an original self-adaptive method based on DP has been developed to enhance the performance in terms of cost with rapid convergence. For the given hypothesis and constraints relative to grid consumption and solar PV production, this method was revealed more efficient than a classical trust-region based approach and a evolutionary algorithms. All investigated procedures take account of the forecasts of consumption and production and aim at generating the best power dispatching for the day ahead. In real-time, an additional control has to be performed so as to ensure the predicted efficiency by correcting the possible forecast errors as described in [14]. Further works will also investigate the generalization of the approach for more complex microgrid architectures including other parameters, e.g. multiple energy storages of different nature (flywheels, electrolyzer-fuel cell association, batteries), various energy rates related to the cost of the grid power depending on the target load (storage charge or consumer feeding) and other grid services such as peak shaving or grid disconnection. Finally, additional studies will focus on the coupling between the sizing of the storage and the energy management aiming at optimizing the tradeoff between the cost of the storage systems and the reduction of the microgrid energy consumption by considering simulations over a longer period of time.

\section{Acknowledgment}

This study has been carried out in the framework of the SMART ZAE national project. The authors thank the project leader INEO-
SCLE-SFE and partners LEVISYS and CIRTEM for their support and Colomiers high school for providing the data of solar irradiation. The SMART ZAE project is supported by ADEME (Agence de l'Environnement et de la Maîtrise de l'Energie)

\section{References}

1] Conti J, Holtberg PD, Beamon JA, Napolitano SA, Schaal AM, Turnure JT. Annual energy outlook. US energy information administration; 2011. Available at: http://www.eia.gov〉.

[2] Celli G, Pilo F, Pisano G, Allegranza V, Cicoria R, Iaria A. Meshed vs. radial MV distribution network in presence of large amount of DG. Power Systems Conference and Exposition IEEE PES; 2004.

[3] Yeleti S, Fu S. Impacts of energy storage on the future power system. North American Power Symposium (NAPS) 2010: 1-7.

[4] Lu D, François B. Strategic framework of an energy management of a microgrid with a photovoltaic-based active generator. ELECTROMOTION, EPE Chapter 'Electric Drives' Joint Symposium; 2009, Lille, France.

[5] Colson CM. A Review of Challenges to Real-Time Power Management of Microgrids. IEEE Power \& Energy Society General Meeting 2009:1-8.

[6] Banos R, Manzano-Agugliarob F, Montoyab FG, Gila C, Alcaydeb A, Gomezc J. Optimization methods applied to renewable and sustainable energy: A review. Renewable and Sustainable Energy Reviews 2011:15:1753-66.

[7] Erdinc O, Uzunoglu M. Optimum design of hybrid renewable energy systems: Overview of different approaches. Renewable and Sustainable Energy Reviews 2012;16:1412-25.

8] Nottrott A, Kleissl J, Washom B. Storage dispatch optimization for gridconnected combined photovoltaic-battery storage systems. Power and Energy Society General Meeting, IEEE 2012:1-7.

[9] Bagherian A, Moghaddas SM. A developed energy management system for a microgrid in the competitive electricity market. IEEE Bucharest Power Tech Conference; 2009.

[10] Harris JM, Hirst JL, Mossinghoff MJ. Combinatorics and Graph Theory. 2nd EditionSpringer; 2000

[11] Hadjipaschalis I, Poullikkas A, Efthimiou V. Overview of current and future energy storage technologies for electric power applications. Renew Sustain Energy Rev 2009;13:1513-22.

[12] Darras C, Sailler S, Thibault C, Muselli M, Poggi P, Hoguet JC, et al. Sizing of photovoltaic system coupled with hydrogen/oxygen storage based on the ORIENTE model. Int J Hydrog Energy 2010;35:3322-32.

[13] Mehdaoui A, Sadok M, Chikhi SA, Mammeri A. Gain énergétique entre deux configurations de système de pompage d'eau photovoltaïque Application au site d'Adrar. Rev Energies Renouv 2010;13:571-82.

[14] Rigo-Mariani R, Sareni B, Roboam X, Astier S, Steinmetz JG, Cahuet E. Off-line and On-line power dispatching strategies for a grid connected commercial building with storage unit. In: IFAC Power Plant and Power System Control; 2012.

[15] Kanchev H, Lu D, Colas F, Lazarov V, François B. Energy management and operational planning of a microgrid with a PV-based active generator for smart grid applications. IEEE Trans Ind Electron 2011;58.

[16] Sechilariu M, Wang B, Locment F. Building integrated photovoltaic system with energy storage and smart grid communication. IEEE Trans Ind Electron 2013;60:1606-18.

[17] Manjili YS, Vega R, Jamshidi M. Cost-efficient environmentally-friendly control of micro-grids using intelligent decision-making for storage energy management. Intell Autom Soft Comput 2013;19:649-70. 
[18] Bradbury K, Pratson L, Patiño-Echeverri D. Economic viability of energy storage systems based on price arbitrage potential in real-time U.S. electricity markets. Appl Energy 2014;114:512-9.

[19] Coleman TF, Li Y. An interior trust region approach for nonlinear minimization subject to bounds. SIAM J Optim 1996;6:418-45.

[20] Petrowski A. A clearing procedure as niching method for genetic algorithms. In: Proceedings of IEEE evolutionary computation; 1996: p. 798-803.

[21] Kennedy J, Eberhart R. Particle swarm optimization. In: IEEE Proceedings of the international conference on neural networks; 1995: p. 1942-8.
[22] Phuangpornpitak N, Tia S, Prommee W, Phuangpompitak W. A study of particle swarm technique for renewable energy power systems. In: International conference on energy and sustainable development: issues and strategies (ESD); 2010: p. 1-6.

[23] Riffoneau Y, Bacha S, Barruel F, Ploix S. Optimal power flow management for grid connected PV systems with batteries. IEEE Trans Sustain Energy 2011;2:309-19.

[24] Bertsekas P. Dynamic programming and optimal control. 2nd Edition, Athena Scientific; 2000. 